\title{
Criterion Validity and Reliability of SF-12 Health Survey Version 2 (SF-12v2) in a Student Population during COVID-19 Pandemic: A Cross-Sectional Study
}

\author{
Ilaria Ruotolo, ${ }^{1}$ Anna Berardi (iD,${ }^{2}$ Giovanni Sellitto, ${ }^{1}$ Francescaroberta Panuccio, ${ }^{1}$ \\ Antonella Polimeni, ${ }^{3}$ Donatella Valente, ${ }^{2,4}$ and Giovanni Galeoto $\mathbb{D}^{2,4}$ \\ ${ }^{1}$ Sapienza University of Rome, Italy \\ ${ }^{2}$ Department of Human Neurosciences, Sapienza University of Rome, Italy \\ ${ }^{3}$ Department of Odontostomatological and Maxillo Faccial Sciences, Sapienza University, Rome, Italy \\ ${ }^{4}$ IRCSS Neuromed, Via Atinense, 18, 86077 Pozzilli, Italy
}

Correspondence should be addressed to Giovanni Galeoto; giovanni.galeoto@uniroma1.it

Received 27 December 2020; Revised 21 June 2021; Accepted 19 July 2021; Published 5 August 2021

Academic Editor: Jan Spijker

Copyright (C) 2021 Ilaria Ruotolo et al. This is an open access article distributed under the Creative Commons Attribution License, which permits unrestricted use, distribution, and reproduction in any medium, provided the original work is properly cited.

\begin{abstract}
Objective. The novel coronavirus SARS-CoV-2, responsible for the COVID-19 pandemic, led to strict domestic quarantine, social isolation policies, and consequently significant psycho-emotional and lifestyle changes. The individual and societal fear and anxiety cause significant stress affecting health-related quality of life (HRQOL). There is evidence of the psychological and mental health effects of the current pandemic on students, who are known to be a vulnerable population. A decrease in physical activity was reported among students, and it is known to contribute to stress levels, which is strongly associated with HRQOL. This study is aimed at evaluating the validity and reliability of SF-12 Health Survey version 2 (SF-12v2) in the assessment of self-perceived quality of life of Italian students following lifestyle changes due to the outbreak of COVID-19. Methods. A cross-sectional study was conducted with university students attending the faculty of Medicine and Surgery or Health Professions. The Physical Component Summary (PCS12) and the Mental Component Summary (MCS12) of SF-12v2 were compared to the Perceived Stress Scale (PSS). Internal consistency was examined using Cronbach's Alpha Coefficient. Concurrent validity was evaluated comparing SF-12v2 values to PSS scores, and the Pearson Correlation Coefficient (PCC) was calculated. Cross-cultural validity was investigated through several analyses for correlations between SF-12v2 scores and the gender of participants, University of Italy, body mass index (BMI), and time spent sitting and exercising. Results. The SF-12v2 questionnaire was administered to 583 medical and health professionals' students in July 2020. Cronbach's Alpha showed acceptable reliability for PCS12 and MCS12. In line with expectations, PCS12 scores differed by BMI groups, while the MCS12 was associated with PSS score and showed differences between genders, BMI groups, time spent sitting, and time spent exercising. Conclusion. The Italian version of SF$12 \mathrm{v} 2$ is a valid and reliable instrument to assess health-related quality of life among medical and health professionals' students.
\end{abstract}

\section{Introduction}

Quality of life (QOL) is a broad multidimensional concept that usually includes subjective evaluations of both positive and negative aspects of life. Health-related quality of life (HRQOL) includes those aspects of quality of life that can be shown to reflect either physical or mental health; it concerns physical, psychological, and social domains of health, and it is broadly accepted as an important outcome measure of health care [1].

The novel coronavirus SARS-CoV-2, responsible for the COVID-19 pandemic, led the various governments to implement strict domestic quarantine and social isolation policies that led people to significant psycho-emotional changes [2]. Regarding Italy, the Civil Protection Department adopted control measures such as information campaigns, closure of 
schools and universities, workplaces, and subsequently lockdown [3]. In addition to the morbidity and mortality due to the coronavirus-19 disease, the adopted response measures also had important physical and psychological consequences for individuals [4]. In fact, an outbreak is associated with considerable psychological disorders, such as depression, anxiety, and fear in specific communities and medical students $[5,6]$. Alternatively, an increase in financial and family stress could be associated with some avoidance behaviors, which would have worsened their mental health and lead to a more passive lifestyle [7]. Sleep problems are also important public health issues when epidemics and disasters occur. This represents a common manifestation of anxiety and depression [8].

It is known that the presence of epidemics accentuates or creates new stressors, including fear and worry for oneself or loved ones, constraints on physical movement and social activities due to quarantine, and sudden and radical lifestyle changes. The unprecedented individual and societal fear and anxiety cause significant stress affecting HRQOL. Additionally, researchers have demonstrated a decrease in the level of outdoor physical activity and an increase in sedentary time during the COVID-19 pandemic as a result of home confinement. There is evidence of the current pandemic's psychological and mental health effects on students, who are known to be a vulnerable population [9]. A recent study indicated an increased percentage of Italian people with high and very high levels of distress compared to the European epidemiological statistics: $53.8 \%$ of respondents rated the psychological impact of the outbreak as moderate or severe, $16.5 \%$ reported moderate to severe depressive symptoms, $28.8 \%$ reported moderate to severe anxiety symptoms, and $8.1 \%$ reported moderate to severe stress levels [5]. It is known that the mental health of college students is significantly affected when faced with public health emergencies, and they require attention, help, and support of the society, families, and colleges [10, 11]. A study was conducted on Italian undergraduate students which showed $48.6 \%$ of the participants from the same student population decreased their physical activity; this result is in line with other researches performed with college students and adults from the United States and France [4].

Another study reported a decrease of physical activity in almost half of participants, where the majority of the students did not modify other habits, for example, diet and smoking habits [3]. A reduction in physical activity is known to contribute to stress levels, which is strongly associated with HRQOL [12].

In many studies, online questionnaires were used for the assessment of HRQOL and stress levels in students and general populations during the lockdown, and also, other surveys such as the World Health Organization Quality of Life(WHOQOL-) BREF questionnaire [13] and the Pittsburgh Sleep Quality Index (PSQI) [14], many studies used the Perceived Stress Scale (PSS) [15].

The SF-12 Health Survey version 2 (SF-12v2) is a generic short-form health survey developed in the USA from the original SF-36. It produces two summary measures evaluating physical and mental self-perceived health; for this reason, it could be a suitable and complete tool to assess the selfperceived quality of life of university students because it allows investigating both the aspects. SF-12v2 has been successfully tested in several Western European countries on large samples of the general population, proving its brevity, comprehensiveness, reliability, validity, and crosscultural applicability [16, 17]. Gandek et al. [18], in a cross-validation study, tested that the SF-12v2 suggested in the original United State study [19] for nine European countries (Denmark, France, Germany, Italy, the Netherlands, Norway, Spain, Sweden, and the United Kingdom). The SF$12 \mathrm{v} 2$, since then, has been extensively used in health status studies involving the general population [20-25] as well as in studies with disease groups. Until now, no study has investigated the physical and psychological effects on students during the outbreak due to COVID-19 using the SF-12v2.

The primary objective of this study is to evaluate the psychometric proprieties of the SF-12v2 in the assessment of self-perceived HRQOL of Italian students after the lifestyle changes due to the outbreak of COVID-19. The secondary objective is to detect different behaviors of the tool in different populations' groups in order to confirm the hypothesis that physical and mental health have been influenced by gender, university of origin (North, Central, and South Italy), body mass index, and number of hours spent sitting or exercising during the lockdown due to COVID-19 pandemic. Specifically, the authors hypothesized the following:

(1) PSS would have had strong association with MCS12 and less strong with PCS12, as studied in previous studies $[26,27]$

(2) PCS12 and MCS12 scores would have had statistically different scores between people from northern/central/southern university, due to different rates of contagion and different restriction measures in these areas

(3) PCS12 scores would have had highest for persons with normal BMI but lower for underweight and overweight as evaluated by Wee et al. [28]

\section{Methods}

A cross-sectional study was conducted by a research group of Sapienza University of Rome and Rehabilitation and Outcome Measures Assessment (ROMA) association to evaluate the psychometric properties of SF-12v2 health survey [2939].

The institutional review board of Sapienza University of Rome approved the study and guaranteed ethical standards and procedures. The procedures followed the 1964 Helsinki declaration and its later amendments or comparable ethical standards. All individual participants included in the study were asked for informed consent. The datasets analyzed during the study are available from the corresponding author.

The study's inclusion criteria were to be university students attending the faculty of Medicine and Surgery or Health Professions in Italian Universities. 
TABLE 1: Demographic characteristics of the sample.

\begin{tabular}{lc}
\hline & $N^{\circ}=583$ \\
\hline Age, mean \pm SD & $23.14 \pm 5.17$ \\
Gender, $N^{\circ}(\%)$ & \\
Female & $404(69.3)$ \\
Male & $179(30.7)$ \\
University, $N^{\circ}(\%)$ & \\
North & $134(23)$ \\
Center & $408(70)$ \\
South and islands & $41(7)$ \\
Body mass index, $N^{\circ}(\%)$ & \\
Underweight & $47(8.1)$ \\
Normal weight & $422(72.4)$ \\
Overweight & $98(16.8)$ \\
Obesity & $16(2.7)$ \\
Time spent sitting, $N^{\circ}(\%)$ & \\
$<6$ hours & $150(25.7)$ \\
$6-12$ hours & $383(65.7)$ \\
$12-18$ hours & $36(6.2)$ \\
$<18$ hours & $14(2.4)$ \\
Time spent exercising, $N^{\circ}(\%)$ & $62(10.6)$ \\
0 hours & $290(49.7)$ \\
1 hours & $175(30)$ \\
2 hours & $34(5.8)$ \\
$>3$ hours & $22(3.9)$ \\
\hline
\end{tabular}

TABLE 2: Exploratory factor analysis of SF-12v2 in Italian University students.

\begin{tabular}{lcc}
\hline & MCS-12 & PCS-12 \\
\hline Item 1 & 0.337 & 0.386 \\
Item 2 & 0.055 & 0.705 \\
Item 3 & 0.025 & 0.679 \\
Item 4 & 0.220 & 0.687 \\
Item 5 & 0.079 & 0.760 \\
Item 6 & 0.724 & 0.144 \\
Item 7 & 0.785 & 0.073 \\
Item 8 & 0.266 & 0.712 \\
Item 9 & 0.788 & 0.083 \\
Item 10 & 0.792 & 0.183 \\
Item 11 & 0.820 & 0.121 \\
Item 12 & 0.695 & 0.222 \\
\hline
\end{tabular}

2.1. Outcome Measures. The SF-12v2 is a shortened version of SF-36v2; it is a self-reported outcome measuring HRQOL. It includes the same health domains as the SF-36 with fewer questions, making it a more practical instrument to evaluate physical and mental health. According to the original manual, it allows scoring of two health component measures: the Physical Component Summary (PCS12) and the Mental Component Summary (MCS12) [40]. The PCS12 and
MCS12 are calculated by using US-derived item weights for response categories following recommendations from the authors of the instrument (which were done after having assessed the equivalence between country-specific and US weights in nine countries). Thus, each of the two health components is scored based on information from all 12 items, but different weights are applied for physical health and mental health, to achieve highest possible independence between the two health components.

The Perceived Stress Scale (PPS) is a 14-item scale used to measure perceived stress. In this study, the Italian version of PSS-10 was used; it is a shorter version of the original one and includes ten items $(1,2,3,6,7,8,9,10,11$, and 14), six negatively stated and four positively stated.

2.2. Procedures and Data Analysis. The research group recruited participants according to the inclusion criteria. A mailing list was used to recruit university students attending the faculty of Medicine and Surgery or Health Professions. All participants gave informed consent and then completed the SF-12v2 questionnaire.

2.3. Factor Structure. Previous studies [40] have found that 6 of the SF-12v2 items $(1,2,3,4,5,8)$ are most strongly associated with physical health, while 6 other items $(6,7,9,10$, $11,12)$ are most strongly associated with mental health. In order to confirm this result, we performed an exploratory factor analysis (EFA) with maximum likelihood factoring. Maximum likelihood and principal axis factoring are the generally recommended extraction methods [41]. Extracted factors were rotated by varimax rotation (orthogonal rotation method), and significant factor loading for EFA was set $>4$ [42]. The appropriateness of sampling was evaluated using the Keiser-Meyer-Olkin (KMO) and Bartlett's test of sphericity.

2.4. Reliability. The most appropriate measures of reliability of the PCS12 and MCS12 use reliability indices for weighted composite scores [43]. However, this approach is difficult, since it requires reliability estimates for each of the 8 subscales of the SF-12, some of which has only 1 item. Therefore, we estimated approximate reliability by using Cronbach's coefficient alpha for the 6 items most strongly associated with physical health and the 6 items most strongly associated with mental health. An alpha coefficient of 0.7 is usually seen as acceptable reliability.

Moreover, in conformity with previous studies on reliability of the tool, in order to evaluate Cronbach's alpha, we used the value of the response choice categories before weighting the indicator variables and computation of aggregate scores $[23,24,44]$. We reverse scored four items $(1,8$, 9 , and 10) so that a higher item value indicates better health for all Sf-12v2 items and summary scales.

2.5. Validity. The criterion validity was evaluated by comparing SF-12v2 values to PSS scores.

The two assessment tools were administered together, and the Pearson Correlation Coefficient (PCC) was calculated. PCC can be interpreted as follows: 0 indicates no linear relationship, $+1 /-1$ indicates perfect positive/negative linear 
TABLE 3: ANOVA analysis for SF-12v2 scores in Italian University students.

\begin{tabular}{|c|c|c|c|c|c|}
\hline & $N$ & $\mathrm{PCS} 12$ mean $\pm \mathrm{SD}$ & $p$ & MCS12 mean \pm SD & $p$ \\
\hline Total & 583 & $54.35 \pm 6.61$ & & $41.43 \pm 12.16$ & \\
\hline \multicolumn{6}{|l|}{ Gender } \\
\hline Female & 404 & $54.36 \pm 6.98$ & \multirow{2}{*}{0.938} & $39.14 \pm 11.82$ & \multirow{2}{*}{$0.001^{*}$} \\
\hline Male & 179 & $54.32 \pm 5.71$ & & $46.62 \pm 11.33$ & \\
\hline \multicolumn{6}{|l|}{ University } \\
\hline North & 134 & $54.82 \pm 5.99$ & \multirow{3}{*}{0.740} & $39.81 \pm 12.30$ & \multirow{3}{*}{0.960} \\
\hline Center & 408 & $54.41 \pm 6.69$ & & $42.15 \pm 11.91$ & \\
\hline South and islands & 41 & $52.16 \pm 7.51$ & & $39.63 \pm 13.72$ & \\
\hline \multicolumn{6}{|l|}{ Body mass index } \\
\hline Underweight & 47 & $52.98 \pm 8.45$ & \multirow{4}{*}{$0.050^{*}$} & $39.99 \pm 12.39$ & \multirow{4}{*}{0.607} \\
\hline Normal weight & 422 & $54.89 \pm 6.04$ & & $41.40 \pm 12.26$ & \\
\hline Overweight & 98 & $53.31 \pm 7.12$ & & $42.56 \pm 11.80$ & \\
\hline Obesity & 16 & $50.44 \pm 9.37$ & & $39.67 \pm 11.38$ & \\
\hline \multicolumn{6}{|l|}{ Time spent sitting } \\
\hline$<6$ hours & 150 & $54.70 \pm 6.18$ & \multirow{4}{*}{0.727} & $43.88 \pm 12.16$ & \multirow{4}{*}{$0.021^{*}$} \\
\hline 6-12 hours & 383 & $54.20 \pm 6.84$ & & $40.58 \pm 11.93$ & \\
\hline 12-18 hours & 36 & $54.90 \pm 6.12$ & & $39.28 \pm 13.17$ & \\
\hline$>18$ hours & 14 & $53.13 \pm 6.4$ & & $44.08 \pm 12.87$ & \\
\hline \multicolumn{6}{|c|}{ Time spent exercising } \\
\hline 0 hours & 62 & $52.86 \pm 8.75$ & \multirow{5}{*}{0.434} & $36.46 \pm 13.61$ & \multirow{5}{*}{$0.007^{*}$} \\
\hline 1 hours & 290 & $54.48 \pm 6.18$ & & $41.75 \pm 11.90$ & \\
\hline 2 hours & 175 & $54.66 \pm 6.79$ & & $41.90 \pm 11.73$ & \\
\hline 3 hours & 34 & $54.61 \pm 5.1$ & & $45.09 \pm 12.72$ & \\
\hline$>3$ hours & 22 & $53.89 \pm 5.75$ & & $42.01 \pm 10.89$ & \\
\hline
\end{tabular}

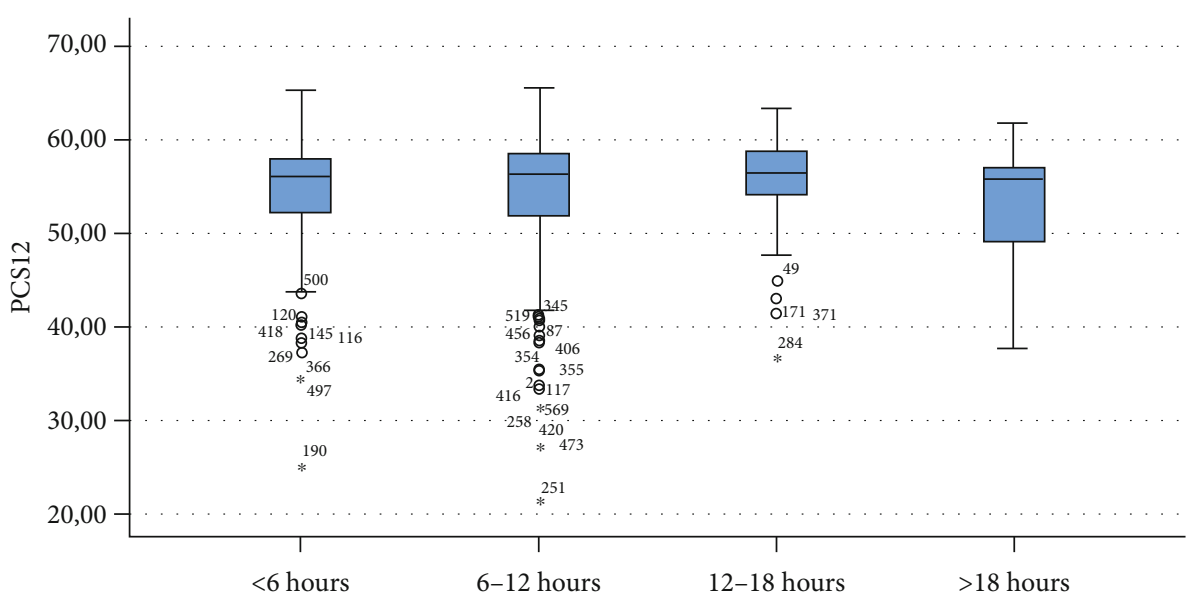

FIgURE 1: Correlation between Physical Component Summary (PCS12) of SF-12 and time spent sitting during the lockdown due to COVID19 pandemic.

relationship, between 0 and \pm 0.3 weak relationship, between \pm 0.3 and \pm 0.7 moderate relationship, and between \pm 0.7 and \pm 1.0 strong relationship.

We also analyzed known group validity [45] through box plots and ANOVA analysis in order to investigate whether
PCS12 or MCS12 differed as hypothesized between gender, BMI group, and number of hours spent sitting and exercising during the lockdown.

All statistical analyses were conducted using Statistical Package for Social Sciences (SPSS). 


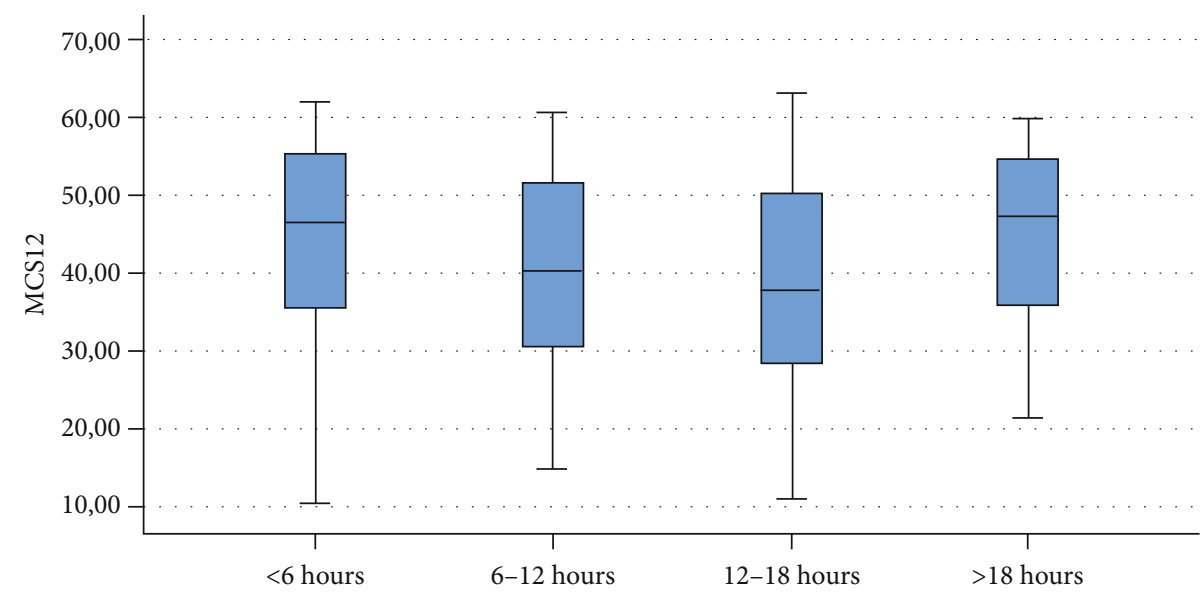

FIGURE 2: Correlation between Mental Component Summary (MCS12) of SF-12 and time spent sitting during the lockdown due to COVID19 pandemic.

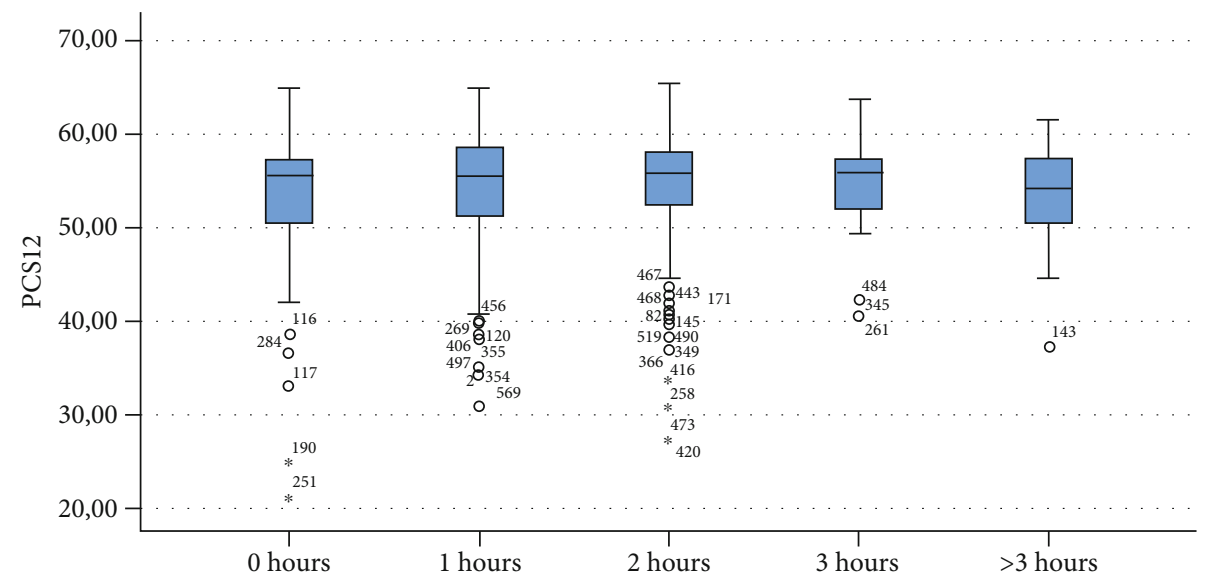

FIguRe 3: Correlation between Physical Component Summary (PCS12) of SF-12 and time spent exercising during the lockdown due to COVID-19 pandemic.

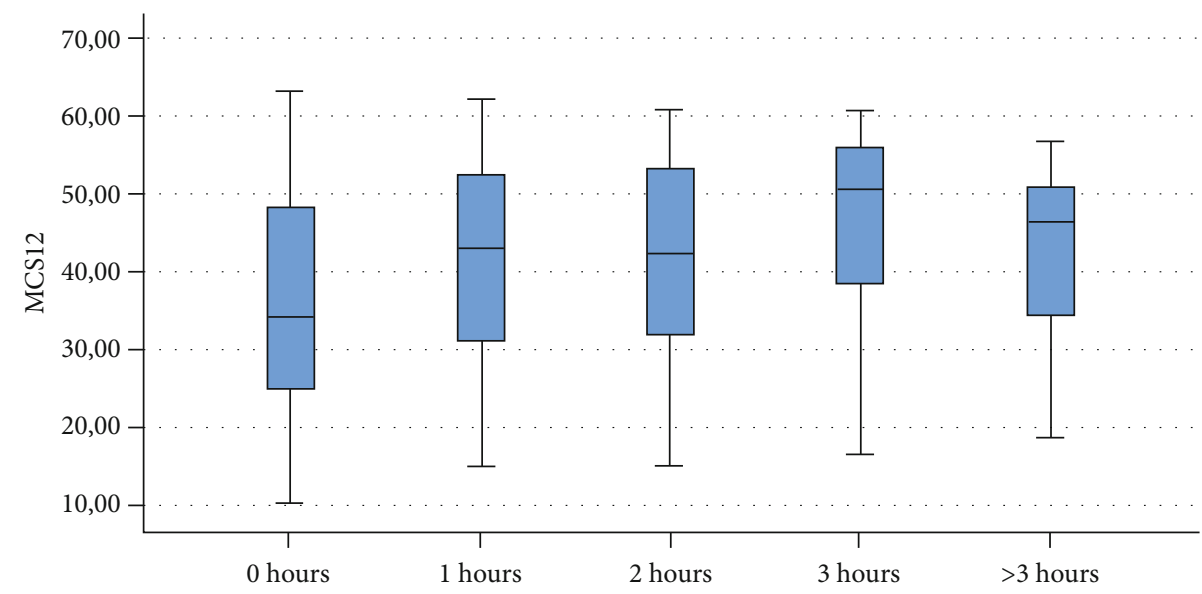

FIGURE 4: Correlation between Mental Component Summary (MCS12) of SF-12 and time spent exercising during the lockdown due to COVID-19 pandemic.

\section{Results}

The SF-12v2 questionnaire was administered together with the PSS to 583 medical and health professionals' students recruited by the Department of Human Neurosciences of Sapienza University of Rome in July 2020. The demographic characteristics of the sample are summarized in Table 1. 


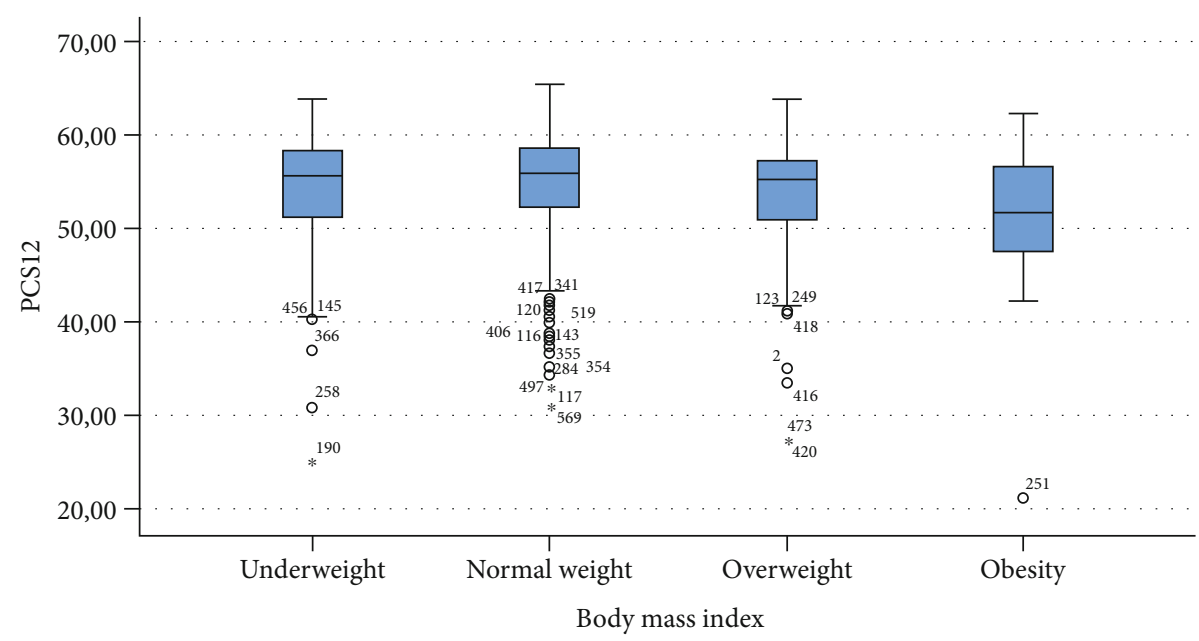

Figure 5: Correlation between Physical Component Summary (PCS12) of SF-12 and body mass index.

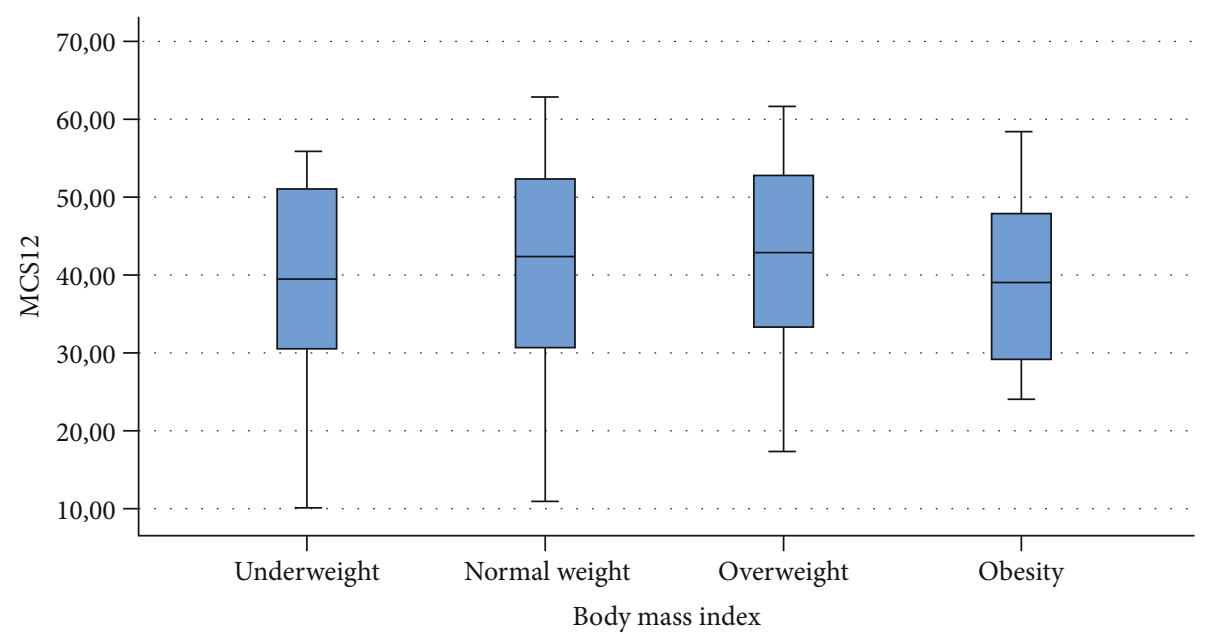

FIGURE 6: Correlation between Mental Component Summary (MCS12) of SF-12 and body mass index.

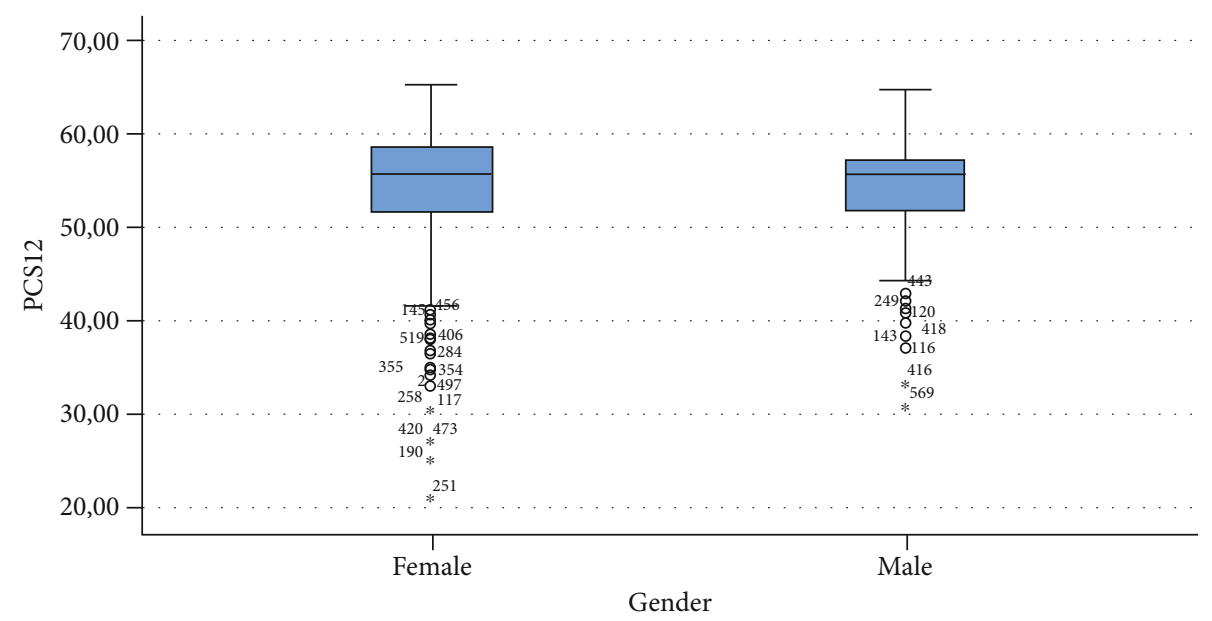

Figure 7: Correlation between Physical Component Summary (PCS12) of SF-12 and gender. 


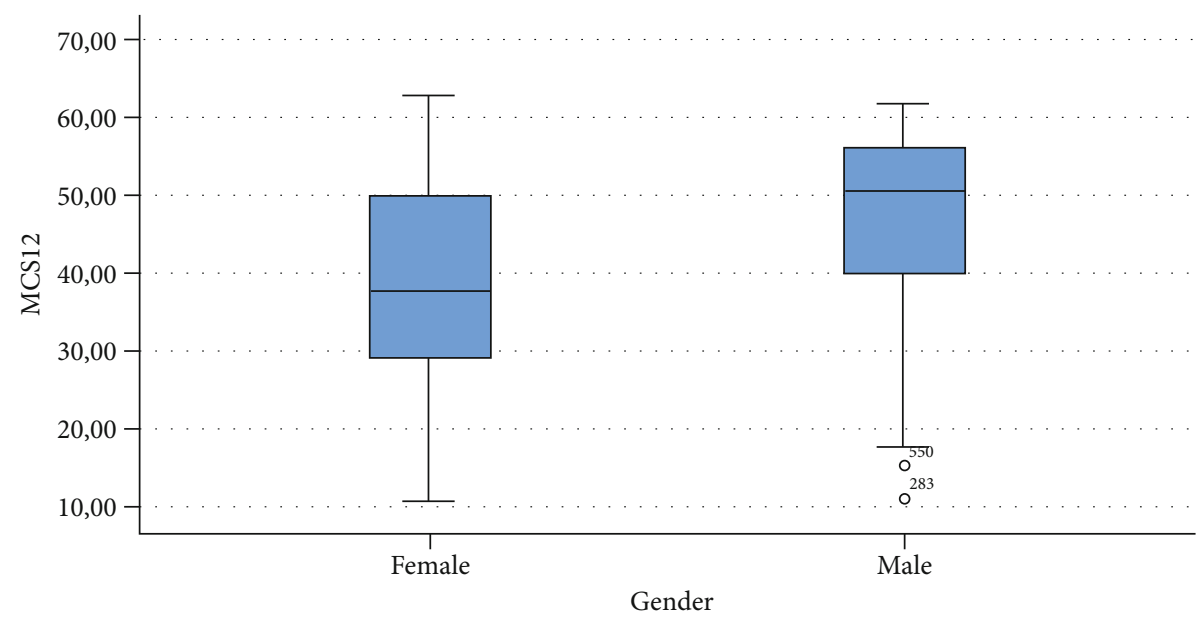

FIGURE 8: Correlation between Mental Component Summary (MCS12) of SF-12 and gender.

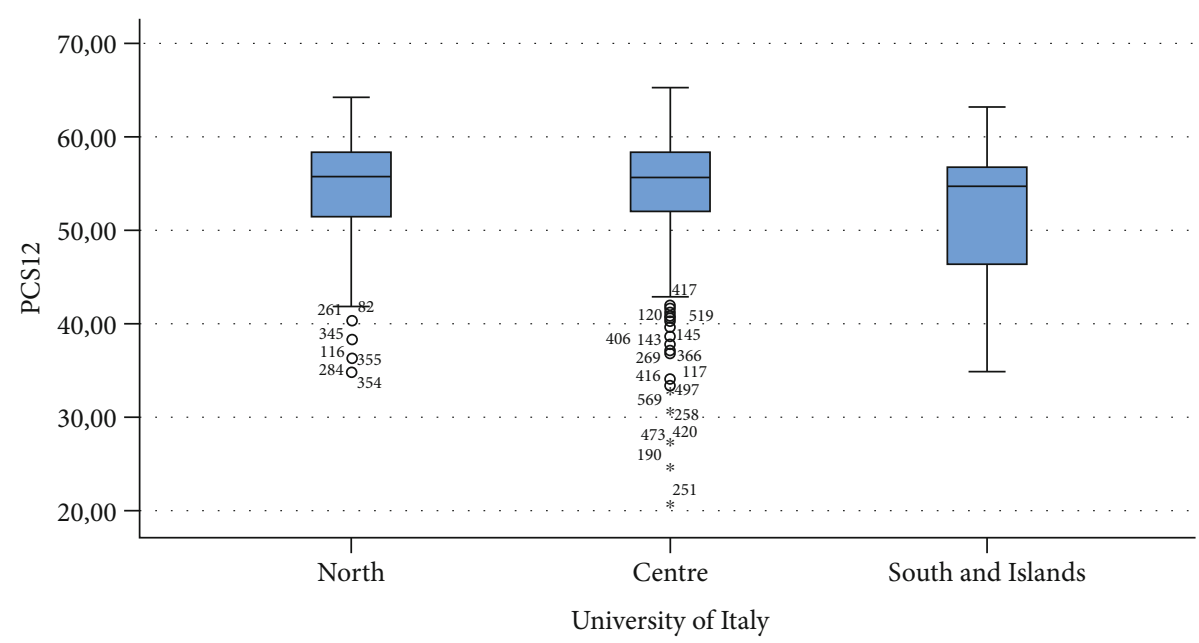

FIgURE 9: Correlation between Physical Component Summary (PCS12) of SF-12 and geographic area of Italy.

The results of the exploratory factor analyses are presented in Table 2 . The Bartlett's test of sphericity has a $p$ value $<0.001$ and the KMO 0.863. This finding indicates that data were suitable for factor analysis. Factor analysis extracted 2 factors out of the 12 items that explained $54.82 \%$ of the variance. As shown in Table 2, factor 1 included 6 items (items $1,2,3,4,5$, and 8$)$, and factor 2 included 6 items $(6,7,9$, $10,11,12)$. These results confirm the allocation presented in the original manual [37].

Alpha coefficient was 0.69 as regards PCS12 of SF-12v2 and 0.84 as regards MCS12. From the "Cronbach's Alpha if Item Deleted" analyses, all items resulted to be necessary for the total subscale.

The correlation between the PSS and the MCS12 was $-0.390(p<0.01)$, while the correlation with the PCS12 was 0.013 .

The ANOVA analysis of known group validity is presented in Table 3 showing a statistically significant difference in MCS12 for gender, time spent sitting, and time spent exercising. A statistically significant difference was found also in PCS12 scores in people with different BMI.
Finally, Figures 1-10 show graphically through box plot differences in mean between PCS12 and MCS12 with time spent sitting and exercising, BMI, and Italian geographic area.

\section{Discussion}

The primary objective of this study was to evaluate the psychometric proprieties of the SF-12v2 in the assessment of self-perceived HRQOL of Italian students after the lifestyle changes due to the outbreak of COVID-19. The secondary objective was to detect different score levels of the tool in different populations' groups in order to confirm the hypothesis that physical and mental health are associated with gender, $\mathrm{BMI}$, and number of hours spent sitting or exercising during the lockdown due to COVID-19 pandemic.

The results of this study showed that SF-12v2 is a reliable and valid tool to assess self-perceived HRQOL in Italian students in terms of internal consistency reliability and construct validity. 


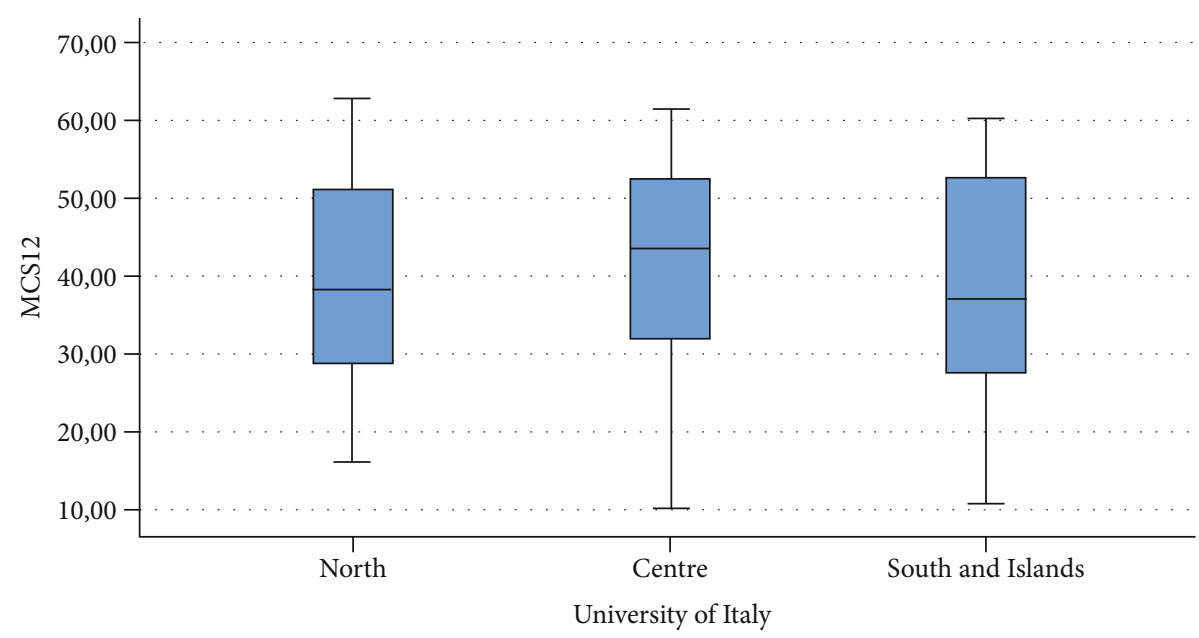

Figure 10: Correlation between Mental Component Summary (MCS12) of SF-12 and geographic area of Italy.

As hypothesized, we found a moderate linear correlation between the PSS scale and MCS12 but no correlation between PSS and PCS12 [26, 27].

We found statistically significant differences in scores of PCS12 in students with different BMIs showing that people with obesity had worse self-assessed physical health compared with those of people with normal weight [28].

As expected, scores of MCS-12 were lower for women than for men, but we did not find a similar difference for PCS12. This study shows statistically significant associations between MCS12 and time spent sitting and exercising during the lockdown due to COVID-19 pandemic. With regard to time spent sitting, lowest scores in the MCS12 were found for the group spending 12-18 hours sitting. Surprisingly, best MCS12 scores were seen in the group spending over 18 hours sitting. However, this may be a spurious result due to the small size of the group $(n=14)$. With regard to time spent exercising, highest MCS12 scores were seen in the groups spending 3 hours or more than 3 hours exercising. This means that students that did not practice physical activity during lockdown reported a lower level of mental health in SF-12v2. The mean value of the MCS12 (41.43) is about ten points below the norm score indicated for SF-12v2 [46]. This result is consistent with the current literature. In fact, other studies conducted on students found that while physical health was above the United States (US) general population norm (50 points), mental health scores of SF-12v2 were lower [47]. It has been demonstrated that increasing physical activity and promoting adequate sleep duration are key health promotion strategies for college students [48]. Regarding mental health, the literature shows increased symptoms of depression, anxiety, and stress related to COVID-19 due to psychosocial stressors such as life disruption, fear of illness, or fear of negative economic effects [49].

As regards the university location, we did not find statistically significant differences in HRQOL scores. North Italy was afflicted with COVID-19 first and has been in a stressful situation for the longest. However, this area had a better situation as regards hospitals and sanitary operation than other areas. Anyway, coronavirus spread rapidly also in the other areas [49].

\section{Conclusion}

This study showed that the Italian version of SF-12v2 is a valid and reliable instrument to assess HRQOL for medical and health professionals' students.

\section{Data Availability}

The data used to support the findings of this study are available from the corresponding author upon request.

\section{Conflicts of Interest}

The authors declare that there is no conflicts of interest.

\section{References}

[1] World Health Organization, Constitution of The World Health Organization, Basic Doc, Forthy-Fifth editionForthy-Fifth edition, , 2006.

[2] P. G. . B. Silva, C. A. L. Oliveira, M. M. F. Borges et al., "Distance learning during social seclusion by COVID-19: improving the quality of life of undergraduate dentistry students," European Journal of Dental Education, vol. 25, no. 1, pp. 124-134, 2021.

[3] F. Gallè, E. A. Sabella, G. Da Molin et al., "Understanding knowledge and behaviors related to COVID-19 epidemic in Italian undergraduate students: the EPICO study," International Journal of Environmental Research and Public Health, vol. 17, no. 10, p. 3481, 2020.

[4] F. Gallè, E. A. Sabella, S. Ferracuti et al., "Sedentary behaviors and physical activity of Italian undergraduate students during lockdown at the time of COVID-19 pandemic," International Journal of Environmental Research and Public Health, vol. 17, no. 17 , p. $6171,2020$.

[5] C. Mazza, E. Ricci, S. Biondi et al., "A nationwide survey of psychological distress among Italian people during the COVID-19 pandemic: immediate psychological responses and associated factors," International Journal of Environmental Research and Public Health, vol. 17, no. 9, p. 3165, 2020.

[6] H. Tian, Y. Xue, R. R. Yao et al., "Humanistic care and psychological counseling on psychological disorders in medical 
students after COVID-19 outbreak," Medicine (Baltimore), vol. 99, no. 33, article e21484, 2020.

[7] Y. Zhang and Z. F. Ma, "Impact of the COVID-19 pandemic on mental health and quality of life among local residents in Liaoning Province, China: a cross-sectional study," International Journal of Environmental Research and Public Health, vol. 17, no. 7, p. 2381, 2020.

[8] S. Wang, Y. Zhang, W. Ding et al., "Psychological distress and sleep problems when people are under interpersonal isolation during an epidemic: a nationwide multicenter cross-sectional study," European Psychiatry, vol. 63, no. 1, article e77, 2020.

[9] C. Son, S. Hegde, A. Smith, X. Wang, and F. Sasangohar, "Effects of COVID-19 on college students' mental health in the United States: interview survey study," Journal of Medical Internet Research, vol. 22, no. 9, article e21279, 2020.

[10] X. Liu, J. Liu, and X. Zhong, "Psychological state of college students during COVID-19 epidemic," SSRN Electronic Journal, vol. 22 , no. 6,2020

[11] J. F. Huckins, A. W. DaSilva, W. Wang et al., "Mental health and behavior of college students during the early phases of the COVID-19 pandemic: longitudinal smartphone and ecological momentary assessment study," Journal of Medical Internet Research, vol. 22, no. 6, article e20185, 2020.

[12] M. Qi, P. Li, W. Moyle, B. Weeks, and C. Jones, "Physical activity, health-related quality of life, and stress among the Chinese adult population during the COVID-19 pandemic," International Journal of Environmental Research and Public Health, vol. 17, no. 18, p. 6494, 2020.

[13] S. M. Skevington, M. Lotfy, K. A. O'Connell, and WHOQOL Group, “The World Health Organization's WHOQOL-BREF quality of life assessment: psychometric properties and results of the international field trial. A Report from the WHOQOL Group," Quality of Life Research, vol. 13, no. 2, pp. 299-310, 2004.

[14] D. J. Buysse, C. F. Reynolds III, T. H. Monk, S. R. Berman, and D. J. Kupfer, "The Pittsburgh Sleep Quality Index: a new instrument for psychiatric practice and research," Psychiatry Research, vol. 28, no. 2, pp. 193-213, 1989.

[15] M. G. Nielsen, E. Ørnbøl, M. Vestergaard et al., “The construct validity of the Perceived Stress Scale," Journal of Psychosomatic Research, vol. 84, pp. 22-30, 2016.

[16] G. Kodraliu, P. Mosconi, N. Groth et al., "Subjective health status assessment: evaluation of the Italian version of the SF-12 health survey. Results from the MiOS Project," Journal of Epidemiology and Biostatistics, vol. 6, no. 3, pp. 305-316, 2001.

[17] X. Luo, M. Lynn George, I. Kakouras et al., "Reliability, validity, and responsiveness of the short form 12-item survey (SF-12) in patients with back pain," Spine, vol. 28, no. 15, pp. 1739-1745, 1976.

[18] B. Gandek, J. E. Ware, N. K. Aaronson et al., "Cross-validation of item selection and scoring for the SF-12 health survey in nine countries: results from the IQOLA project," Journal of Clinical Epidemiology, vol. 51, no. 11, pp. 1171-1178, 1998.

[19] J. E. Ware Jr., M. Kosinski, and S. D. Keller, “A 12-item shortform health survey: construction of scales and preliminary tests of reliability and validity," Medical Care, vol. 34, no. 3, pp. 220-233, 1996.

[20] A. G. Campolina, R. V. M. Lopez, E. P. Nardi, and M. B. Ferraz, "Quality of life in a sample of Brazilian adults using the generic SF-12 questionnaire," Revista da Associação Médica Brasileira, vol. 64, no. 3, pp. 234-242, 2018.
[21] N. Kontodimopoulos, E. Pappa, D. Niakas, and Y. Tountas, "Validity of SF-12 summary scores in a Greek general population," Health and Quality of Life Outcomes, vol. 5, no. 1, p. 55, 2007.

[22] C. O. Larson, D. Schlundt, K. Patel, K. Beard, and M. Hargreaves, "Validity of the SF-12 for use in a lowincome African American community-based research initiative (REACH 2010)," Preventing Chronic Disease, vol. 5, p. A44, 2008.

[23] C. E. Mbada, A. S. Awokoya, O. O. Oyewole et al., "Translation, cross-cultural adaptation and psychometric evaluation of Yoruba version of the short-form 12 health survey," Annali di Igiene, vol. 33, pp. 254-267, n.d..

[24] A. A. Ibrahim, M. O. Akindele, S. O. Ganiyu et al., "The Hausa 12-item short-form health survey (SF-12): translation, crosscultural adaptation and validation in mixed urban and rural Nigerian populations with chronic low back pain," PLoS One, vol. 15, no. 5, article e0232223, 2020.

[25] K. Młyńczak and D. Golicki, "Psychometric properties of the Polish version of SF-12v2 in the general population survey," Expert Review of Pharmacoeconomics \& Outcomes Research, pp. 1-8, 2021.

[26] B. Altunan, A. Unal, A. Bingöl, F. Dilek, and D. Girgin, "Coping with stress during the first wave of the COVID-19 pandemic by Turkish people with multiple sclerosis: the relationship between perceived stress and quality of life," Multiple Sclerosis and Related Disorders, vol. 53, p. 103039, 2021.

[27] N. A. Awadh, A. I. Aziz, S. N. Yaseen, S. A. Abdulameer, M. N. Sahib, and O. Q. Al-Lela, "A comparison study of perceived stress and quality of life among Master of Pharmacy and non-pharmacy master's students," Pharmacy Education, vol. 13, pp. 22-28, 2013.

[28] C. C. Wee, R. B. Davis, and M. B. Hamel, "Comparing the SF12 and SF-36 health status questionnaires in patients with and without obesity," Health and Quality of Life Outcomes, vol. 6, no. 1, p. 11, 2008.

[29] F. Manti, F. Giovannone, and C. Sogos, "Parental stress of preschool children with generalized anxiety or oppositional defiant disorder," Frontiers in Pediatrics, vol. 7, 2019.

[30] L. D’Alvia, E. Pittella, F. Fioriello et al., "Heart rate monitoring under stress condition during behavioral analysis in children with neurodevelopmental disorders," in 2020 IEEE International Symposium on Medical Measurements and Applications (MeMeA), pp. 1-6, Bari, Italy, June 2020.

[31] E. Catino, M. di Trani, F. Giovannone et al., "Screening for developmental disorders in 3- and 4-year-old Italian children: a preliminary study," Frontiers in Pediatrics, vol. 5, 2017.

[32] G. Levi, V. Colonnello, R. Giacchè, M. L. Piredda, and C. Sogos, "Building words on actions: verb enactment and verb recognition in children with specific language impairment," Research in Developmental Disabilities, vol. 35, no. 5, pp. 1036-1041, 2014.

[33] A. F. Auletta, S. Cupellaro, L. Abbate et al., "SCORS-G and card pull effect of TAT stories: a study with a nonclinical sample of children," Assessment, vol. 27, no. 6, pp. 1368-1377, 2020.

[34] A. Berardi, E. Regoli, M. Tofani et al., "Tools to assess the quality of life in patients with Parkinson's disease: a systematic review," Expert Review of Pharmacoeconomics \& Outcomes Research, vol. 21, no. 1, pp. 55-68, 2020.

[35] F. Panuccio, G. Galeoto, M. A. Marquez et al., "Internal consistency and validity of the Italian version of the Jebsen- Taylor 
hand function test (JTHFT-IT) in people with tetraplegia," Spinal Cord, vol. 59, no. 3, pp. 266-273, 2021.

[36] A. Berardi, F. Panuccio, L. Pilli, M. Tofani, D. Valente, and G. Galeoto, "Evaluation instruments for executive functions in children and adolescents: a systematic review," Expert Review of Pharmacoeconomics \& Outcomes Research, pp. 1$12,2021$.

[37] F. Miniera, A. Berardi, F. Panuccio, D. Valente, M. Tofani, and G. Galeoto, "Measuring environmental barriers: validation and cultural adaptation of the Italian version of the Craig Hospital Inventory of Environmental Factors (CHIEF) scale," Occupational Therapy in Health Care, vol. 34, no. 4, pp. 373-385, 2020.

[38] F. Panuccio, G. Galeoto, M. A. Marquez et al., "General Sleep Disturbance Scale (GSDS-IT) in people with spinal cord injury: a psychometric study," Spinal Cord, vol. 58, no. 11, pp. 1183-1188, 2020.

[39] F. Panuccio, A. Berardi, M. A. Marquez et al., "Development of the Pregnancy and Motherhood Evaluation Questionnaire (PMEQ) for evaluating and measuring the impact of physical disability on pregnancy and the management of motherhood: a pilot study," Disability and Rehabilitation, vol. 4, pp. 1-7, 2020.

[40] J. E. Ware, M. Kosinski, and S. Keller, How to Score the SF12 Physical and Mental Health Summary Scales, New Engloand Medical Center, Boston, MA, Second edition, 1995.

[41] L. R. Fabrigar, D. T. Wegener, R. C. MacCallum, and E. J. Strahan, "Evaluating the use of exploratory factor analysis in psychological research," Psychological Methods, vol. 4, no. 3, pp. 272-299, 1999.

[42] A. Costello and J. Osborne, "Best practices in exploratory factor analysis: four recommendations for getting the most from your analysis," Practical Assessment, Research and Evaluation, vol. 10, 2005.

[43] M. Maruish, User's Manual for the SF-12v2 Health Survey, 3rd edition3rd edition, , 2012.

[44] C. Haddad, H. Sacre, S. Obeid, P. Salameh, and S. Hallit, "Validation of the Arabic version of the "12-item short-form health survey" (SF-12) in a sample of Lebanese adults," Archives of Public Health, vol. 79, no. 1, p. 56, 2021.

[45] C. A. C. Prinsen, L. B. Mokkink, L. M. Bouter et al., "COSMIN guideline for systematic reviews of patient-reported outcome measures," Quality of Life Research, vol. 27, no. 5, pp. 11471157, 2018.

[46] Y. Ge, S. Xin, D. Luan et al., "Association of physical activity, sedentary time, and sleep duration on the health-related quality of life of college students in Northeast China," Health and Quality of Life Outcomes, vol. 17, no. 1, p. 124, 2019.

[47] M. E. Ogunsanya, B. A. Bamgbade, A. V. Thach, P. Sudhapalli, and K. L. Rascati, "Determinants of health-related quality of life in international graduate students," Currents in Pharmacy Teaching \& Learning, vol. 10, no. 4, pp. 413-422, 2018.

[48] A. Remuzzi and G. Remuzzi, "COVID-19 and Italy: what next?,” Lancet, vol. 395, no. 10231, pp. 1225-1228, 2020.

[49] C. Moreno, T. Wykes, S. Galderisi et al., "How mental health care should change as a consequence of the COVID-19 pandemic," The Lancet Psychiatry, vol. 7, no. 9, pp. 813-824, 2020. 